\title{
End Face Damage and Fiber Fuse Phenomena in Single-Mode Fiber-Optic Connectors
}

\author{
Yoshito Shuto \\ Ofra Project, Iruma 358-0023, Japan \\ Correspondence should be addressed to Yoshito Shuto; ofra@tuba.ocn.ne.jp
}

Received 17 January 2016; Revised 22 May 2016; Accepted 30 May 2016

Academic Editor: Roberto Proietti

Copyright ( 2016 Yoshito Shuto. This is an open access article distributed under the Creative Commons Attribution License, which permits unrestricted use, distribution, and reproduction in any medium, provided the original work is properly cited.

\begin{abstract}
The evolution of both the core melting and fiber fuse phenomena in a single-mode fiber-optic connector was studied theoretically. Carbon black was chosen as a light-absorbent material. A thin absorbent layer with a thickness of $1 \mu \mathrm{m}$ order was assumed to be formed between the fiber end faces in the connector. When a high-power laser operating at 1.48 or $1.55 \mu \mathrm{m}$ was input into the connector, the temperature on the fiber core surface increased owing to heat conduction from the light-absorbent material. The heat flow process of the core, which caused the core to melt or the fiber fuse phenomenon, was theoretically calculated with the explicit finite-difference method. The results indicated that initial attenuation of less than $0.5 \mathrm{~dB}$ was desirable to prevent core fusion in the connectors when the input $1.48 \mu \mathrm{m}$ laser power was $1 \mathrm{~W}$. It was found that a core temperature of more than $4000 \mathrm{~K}$ was necessary to generate and maintain a fiber fuse.
\end{abstract}

\section{Introduction}

Owing to the progress of dense wavelength division multiplexing (DWDM) technology using an optical-fiber amplifier, we can exchange large amounts of data at a rate of over $60 \mathrm{Tbits} / \mathrm{s}$ [1]. However, it is widely recognized that the maximum transmission capacity of a single strand of fiber is rapidly approaching its limit of $\sim 100 \mathrm{Tbits} / \mathrm{s}$ owing to the optical power limitations imposed by the fiber fuse phenomenon and the finite transmission bandwidth determined by opticalfiber amplifiers [2]. To overcome these limitations, space division multiplexing (SDM) technology using a multicore fiber (MCF) was proposed [3].

The fiber fuse phenomenon was first observed in 1987 by British scientists [4-7]. Several review articles [8-12] have been recently published that cover many aspects of the current understanding of fiber fuses.

A fiber fuse can be generated by bringing the end of a fiber into contact with an absorbing material or by melting a small region of a fiber using an arc discharge of a fusion splice machine [4]. If a fiber fuse is generated, an intense bluewhite flash occurs in the fiber core, and this flash propagates along the core in the direction of the optical power source at a velocity on the order of $1 \mathrm{~m} / \mathrm{s}$. Fuses are terminated by gradually reducing the laser power to a termination threshold at which the energy balance at a fuse is broken.

When a fiber fuse is generated, the core layer in which the fuse propagates is seriously damaged, and the damaged fiber cannot be used in an optical communication system. The damage has the form of periodic or nonperiodic bulletshaped cavities left in the core [13-21].

When optical signals are transmitted over a long distance using single-mode optical fibers (SMFs), it is necessary to connect long optical fibers along the transmission path. Optical connectors for SMFs were developed for this purpose. Several research institutes have studied the high-power performance of single-mode fiber-optic connectors [22-25].

One of the most common types of degradation observed in the connectors is related to end face contamination, often induced by plug/unplug operations. The contamination in optical connectors is attributed to dust or other organic particles, which are mainly produced during network installation as a result of handling by human operators. When the plug/unplug procedure is performed with contaminated connectors, the impurities can enter the fiber core region. These adherent impurities act as absorbing centers, 
where the surrounding material is heated to sufficiently high temperatures to induce permanent damage. The temperature rise in the connector may also trigger the fiber fuse effect.

The high-power damage phenomenon in fiber-optic connectors was previously investigated from the viewpoint of the adhesion of absorbing organic materials, such as carbonblack-doped resin $[22,25]$ and a thin layer of carbon black [24], on the core end faces in the connectors. Carbon black was used to represent organic contaminants in these studies.

De Rosa et al. prepared mated connector pair sets that consisted of end faces with carbon black uniformly covering the fiber cores [22]. These contaminated samples were prepared using a carbon-black-doped UV-curable acrylate resin. A thin, even layer of solution was applied to the end face of one connector of the mated pair and was cured using UV light to provide a known end face condition. Samples contaminated with $5 \mathrm{wt} \%$ carbon-black-doped acrylate resin exhibited end face damage at an initial laser power $P_{0}$ of $49 \mathrm{~mW}$ when they were exposed to CW laser light with a wavelength $\lambda_{0}$ of $1.55 \mu \mathrm{m}$ [22].

Seo et al. reported that optical connectors with lightabsorbing contaminants such as carbon black-doped epoxy resin and/or oil-based black ink showed end face damage at $P_{0}=2 \mathrm{~W}$ when exposed to laser light with $\lambda_{0}=1.48 \mu \mathrm{m}$ [25].

Domingues et al. examined the high-power damage of fiber core end faces covered with carbon black [24]. Contaminated samples were prepared using a carbon black aqueous solution to obtain initial attenuation IA in the range of 2-10 dB. Samples with IA $\geq 4 \mathrm{~dB}$ exhibited end face damage at $P_{0}=1 \mathrm{~W}$ when exposed to CW laser light with $\lambda_{0}=1.48 \mu \mathrm{m}$, and the fiber fuse effect occurred in the samples with the passage of time at $1.5 \mathrm{~W}$ [24]. An IA of $4 \mathrm{~dB}$ corresponds to an optical absorption coefficient $\alpha$ of $9.2 \times 10^{5} \mathrm{~m}^{-1}$ when the thickness of the contaminant is about $1 \mu \mathrm{m}$. The value of $\alpha$ for the contaminant is closely related to the generation of end face damage and/or the fiber fuse effect.

In this paper the author begins by estimating the $\alpha$ value for carbon black. Then, using this value, the non-steadystate thermal conduction process in the contaminated end face of an optical connector is theoretically studied using the explicit finite-difference technique and the thermochemical $\mathrm{SiO}_{x}$ production model for SMFs [26].

\section{Absorption Coefficient of Carbon Black}

The optical properties (or constants) of materials are usually characterized by two parameters, the index of refraction $n$ and extinction coefficient $k$. The optical absorption coefficient $\alpha$ is related to $k$ and $\lambda_{0}$ by [27]

$$
\alpha=\frac{4 \pi k}{\lambda_{0}} .
$$

Graphite, which is the raw material of carbon black, has a stratified molecular structure. In each layer, many carbon atoms are tightly packed into a two-dimensional honeycomb lattice [28]. The optical constants of graphite have been estimated in the visible and ultraviolet regions $[29,30]$. Values of $n=2.73$ and $k=1.40$ were reported at $\lambda_{0}=0.63 \mu \mathrm{m}$ [30].

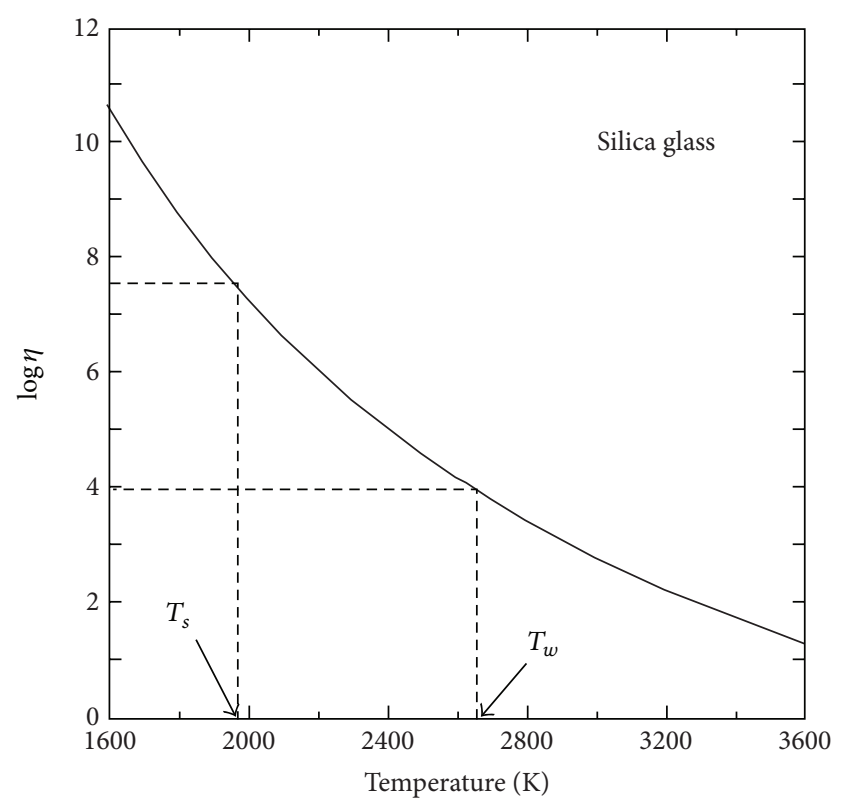

Figure 1: Viscosity of silica glass as a function of temperature.

Using (1) and the optical constants, the absorption coefficient of graphite is estimated to be $\alpha=2.79 \times 10^{7} \mathrm{~m}^{-1}$. This value is of about three orders of magnitude larger than the $\alpha$ values $\left(10^{4} \mathrm{~m}^{-1}\right.$ order) $[6,31]$ required for fiber fuse generation.

The melting temperature of graphite is $4800 \pm 100 \mathrm{~K}$ [32], and liquid carbon exists at high temperature of $>4800 \mathrm{~K}$ [33]. Carbon vapour containing $C_{1}$ to $C_{7}$ species was measured at the temperature $(T)$ of $5000-10000 \mathrm{~K}$ [34]. As the optical constants of liquid carbon and carbon vapour are unknown, $\alpha\left(=2.79 \times 10^{7} \mathrm{~m}^{-1}\right)$ was used throughout the calculation process.

\section{Deformation Temperature of Silica Glass}

To generate end face damage, the temperature of the core layer must reach a critical value, where silica glass can be readily deformed. This critical temperature is known as the working point, which is related to the viscosity of the glass.

The working point $\left(T_{w}\right)$ of a glass is defined as the temperature at which it has a viscosity of $10^{4} \mathrm{P}$ [35]. On the other hand, the softening point $\left(T_{s}\right)$ is the temperature at which it has a viscosity of $10^{7.6} \mathrm{P}$ [35].

The relationship between the viscosity $\eta(\mathrm{P})$ and temperature $T(\mathrm{~K})$ of silica glass (fused silica) is given as follows $[36,37]$ :

$$
\log \eta=-6.24+\frac{26950}{T} .
$$

The $\eta$ values of silica glass are shown in Figure 1 as a function of $T$.

$\eta$ decreases with increasing $T$. Using the $\eta$ data shown in Figure 1, the $T_{w}$ and $T_{s}$ values were estimated to be $T_{w}=$ $2632 \mathrm{~K}$ and $T_{s}=1947 \mathrm{~K}$. 


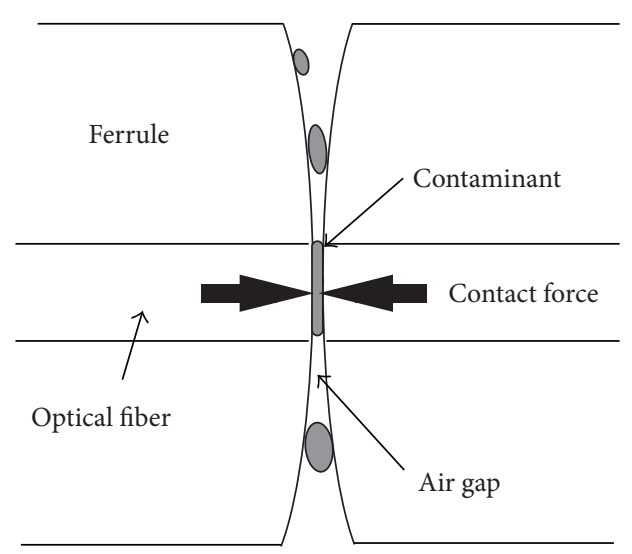

FIGURE 2: Schematic view of ferrule end faces with adhering contaminant.

$T_{s}$ is slightly lower than the melting point $\left(T_{m}=1973 \mathrm{~K}\right)$ of silica glass. Moreover, $T_{w}$ is about $660 \mathrm{~K}$ higher than $T_{m}$.

In the next section, the thermal conduction behavior within contaminated end faces of fiber-optic connectors is investigated by numerical computation using the $\alpha$ values estimated above.

\section{Heat Conduction Behavior in Contaminated Optical-Fiber Connector}

An SMF-28 optical fiber is assumed to be set in the center of a ferrule. This fiber has an outer radius of $r_{f}(=62.5 \mu \mathrm{m})$, a core radius of $a(=4.1 \mu \mathrm{m})$, and a refractive index difference of $\Delta=0.36 \%$.

When two connector plugs with ferrules are joined in an adaptor, compressive contact forces (about $6 \mathrm{~N}$ for the SC-type connector [38]) are generated on the ferrule end faces. These compressive forces result from the difference between the spring compressive force of the plug and the gauge retention force of the adaptor $[39,40]$. The compressive forces deform the ferrule tip and compress the optical fiber held in the ferrule. When the optical fiber with the outer radius of $r_{f}=62.5 \mu \mathrm{m}$ is compressed by the compressive force (about $6 \mathrm{~N}$ ), high pressure of about $0.5 \mathrm{GPa}$ (5000 atm) acts on the fiber end faces.

It is considered that the contaminant (carbon black) enters the gap between the ferrule end faces as shown in Figure 2.

The adhering contaminant is compressed by the compressive contact force to form a thin absorbent layer between the end faces of optical fibers facing each other. A schematic view of the absorbent layer between the optical-fiber end faces is shown in Figure 3, where $\alpha_{a}$ and $\Delta L_{a}$ are the absorption coefficient and the thickness of the absorbent, respectively.

The $\alpha_{a}$ value of the contaminant is very large as described above. Thus, it can be expected that when laser light enters the core layer shown in Figure 3, it is efficiently absorbed near the incident interface with the core, and the generation of heat takes place near this interface.

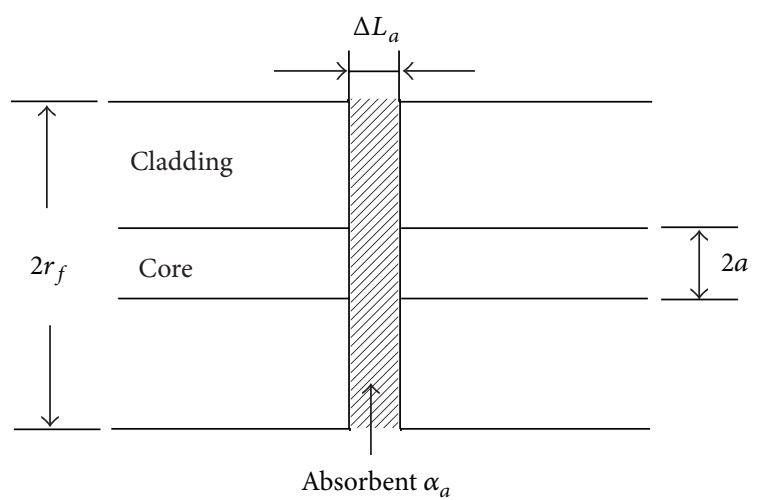

FIGURE 3: Schematic view of absorbent layer between optical-fiber end faces.

To verify this prediction, the author theoretically studied the non-steady-state thermal conduction process in the region near the core end faces in Figure 3 using the explicit finite-difference technique. In the calculation, it was assumed that the initial temperature of the absorbent layer was equal to the atmosphere temperature ( $=298 \mathrm{~K})$.

4.1. End Face Damage Caused by Carbon Black Adhesion. First the author investigated the temperature distribution of core end face in the experiments carried out by De Rosa et al. [22]. In their experiments, the core end face was in contact with an absorbent layer consisting of $5 \mathrm{wt} \%$ carbon black-doped UV-curable acrylate. It was assumed that laser light of wavelength $\lambda_{0}=1.55 \mu \mathrm{m}$ and initial laser power $P_{0}=49 \mathrm{~mW}$ was incident to the optical fiber held in the ferrule (see Figure 2). The value of $\alpha_{a}$ for the absorbent layer was estimated to be about $1.40 \times 10^{6} \mathrm{~m}^{-1}$ by multiplying $\alpha\left(2.79 \times 10^{7} \mathrm{~m}^{-1}\right)$ for graphite by $5 \%$.

The area in the numerical calculation had a length of $2 L(=$ $2 \mathrm{~mm})$ in the axial $(z)$ direction and a width of $2 r_{f}(=125 \mu \mathrm{m})$ in the radial $(r)$ direction. There were 24 and 4000 divisions in the $r$ and $z$ directions, respectively, and the calculation time interval was set to $1 \mathrm{~ns}$. It was assumed that the absorbent layer was located at the center of the fiber (length $2 L$ ) and that the length $\Delta L_{a}$ of the layer was $1 \mu \mathrm{m}$.

It is well known that UV-curable acrylate resin is pyrolyzed at $350-450 \mathrm{~K}$ [41] and charred at high temperatures.

Therefore, in the heat conduction calculation, the author used the following values of $\lambda\left(\mathrm{W} \mathrm{m}^{-1} \mathrm{~K}^{-1}\right), \rho\left(\mathrm{kg} \mathrm{m}^{-3}\right)$, and $C_{p}\left(\mathrm{~J} \mathrm{~kg}^{-1} \mathrm{~K}^{-1}\right)$ in each temperature range.

(1) Parameters of acrylate resin in the temperature range from room temperature ( $298 \mathrm{~K}$ ) to $450 \mathrm{~K}$ [42]:

$$
\begin{aligned}
C_{p} & =1400, \\
\lambda & =0.21, \\
\rho & =1190 .
\end{aligned}
$$




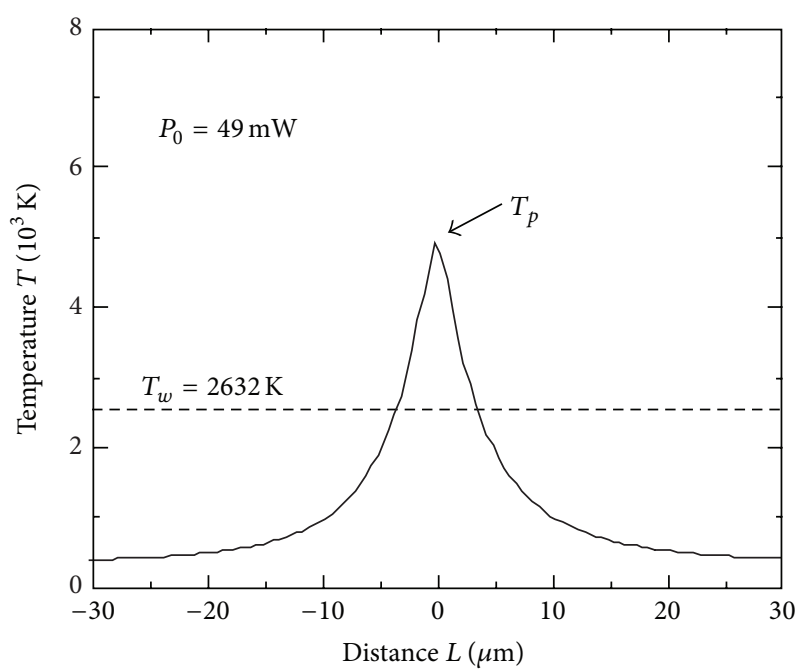

Figure 4: Temperature field around carbon-black-doped UV-curable acrylate layer placed between optical fibers after $100 \mu \mathrm{s}$ when $P_{0}=$ $49 \mathrm{~mW}$ and $\lambda_{0}=1.55 \mu \mathrm{m}$.

(2) Parameters of coal for $T>450 \mathrm{~K}[42]$ are

$$
\begin{aligned}
C_{p} & =1260, \\
\lambda & =0.28, \\
\rho & =1350 .
\end{aligned}
$$

The temperature field of the core center along the $z$ direction was calculated at a time of $100 \mu$ s after the incidence of the $49 \mathrm{~mW}$ laser light. The calculated result is shown in Figure 4.

The heat generated in the absorbent layer is transferred to the neighboring core layers of the optical fibers. At a time of $100 \mu \mathrm{s}$ after laser light incidence, the peak temperature $\left(T_{p}\right)$ of $4800 \mathrm{~K}$ or above occurs in the immediate neighborhood of the absorbent layer (see Figure 4). As a result, the temperatures of the regions of about 4 and $3 \mu \mathrm{m}$ depth in the left and right core layers become higher than the working point $\left(T_{w}=2632 \mathrm{~K}\right)$ of silica glass. In these heated core regions, it can be expected that the melting and flow of silica glass will occur locally and that the surfaces of the core layers will be damaged as observed by De Rosa et al. [22].

Next the author studied the temperature distribution of the core end face in the experiments carried out by Domingues et al. [24]. In their experiments, the core end face was in contact with an absorbent layer produced by spreading carbon black. It was assumed that laser light of wavelength $\lambda_{0}=1.48 \mu \mathrm{m}$ and initial power $P_{0}=1 \mathrm{~W}$ was incident to the optical fiber held in the ferrule (see Figure 2). The length $\Delta L_{a}$ of the absorbent layer and the calculation time interval were assumed to be $1 \mu \mathrm{m}$ and $1 \mathrm{~ns}$, respectively.

The relationship between $\alpha_{a}\left(\mathrm{~m}^{-1}\right)$ and the initial attenuation IA $(\mathrm{dB})$ of the absorbent layer is given by

$$
\alpha_{a}=0.23026 \frac{\mathrm{IA}}{\Delta L_{a}} .
$$

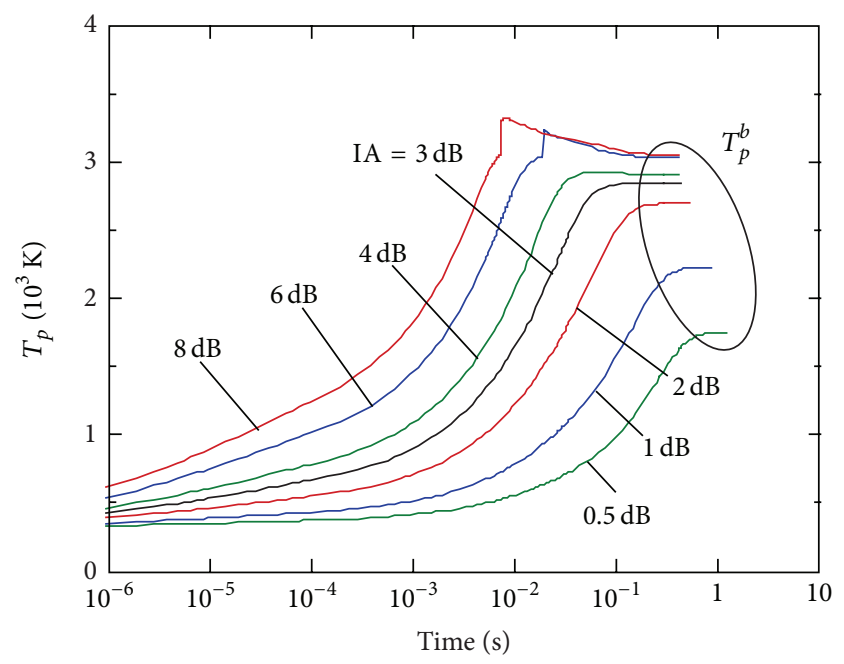

FIGURE 5: Peak temperatures around carbon black layers with IA $=0.5-8 \mathrm{~dB}\left(\Delta L_{a}=1 \mu \mathrm{m}\right)$ spread between optical fibers versus irradiation time when $P_{0}=1 \mathrm{~W}$ and $\lambda_{0}=1.48 \mu \mathrm{m}$.

In the calculation, the following thermal conduction parameters of carbon black were used: $\lambda=98 \mathrm{~W} \mathrm{~m}^{-1} \mathrm{~K}^{-1}$, $\rho=1900 \mathrm{~kg} \mathrm{~m}^{-3}$, and $C_{p}=710 \mathrm{~J} \mathrm{~kg}^{-1} \mathrm{~K}^{-1}$, which are the parameters of black lead [43].

The $T_{p}$ values around absorbent layers with $\mathrm{IA}=0.5-$ $8 \mathrm{~dB}$ were calculated as a function of the irradiation time after the incidence of the $1 \mathrm{~W}$ laser light. The calculated results are shown in Figure 5.

As shown in Figure 5, $T_{p}$ increased with increasing time and approached a certain temperature $T_{p}^{b}$ with the passage of time, where $T_{p}^{b}$ is the temperature at which the balance of heat is achieved in the absorbent layer.

In the case of a heat source in part of the core layer, the nonsteady heat conduction equation for the temperature field $T(r, z, t)$ in an SMF is given by [44]

$$
\rho C_{p} \frac{\partial T}{\partial t}=\lambda\left(\frac{\partial^{2} T}{\partial r^{2}}+\frac{1}{r} \frac{\partial T}{\partial r}+\frac{\partial^{2} T}{\partial z^{2}}\right)+\dot{Q},
$$

where the first term on the right of (6) expresses the diffusion or dissipation of the heat in the optical fiber and the absorbent layer. The last term $\dot{Q}$ in (6) represents the heat source resulting from light absorption, which is mainly required for the absorbent layer between the optical fibers. $\dot{Q}$ can be expressed by

$$
\dot{Q}=\alpha I,
$$

where $I$ is the optical power intensity in the core layer, which can be estimated by dividing the incident optical power $P_{0}$ by the effective area $A_{\text {eff }}$ of the fiber.

When laser light enters the absorbent layer, heat is produced in the layer by optical absorption of the incident light. The heat generated by optical absorption in the layer is effectively dissipated by the heat conduction because the thermal conductivity $\lambda$ of the absorbent (carbon black) is large. As 


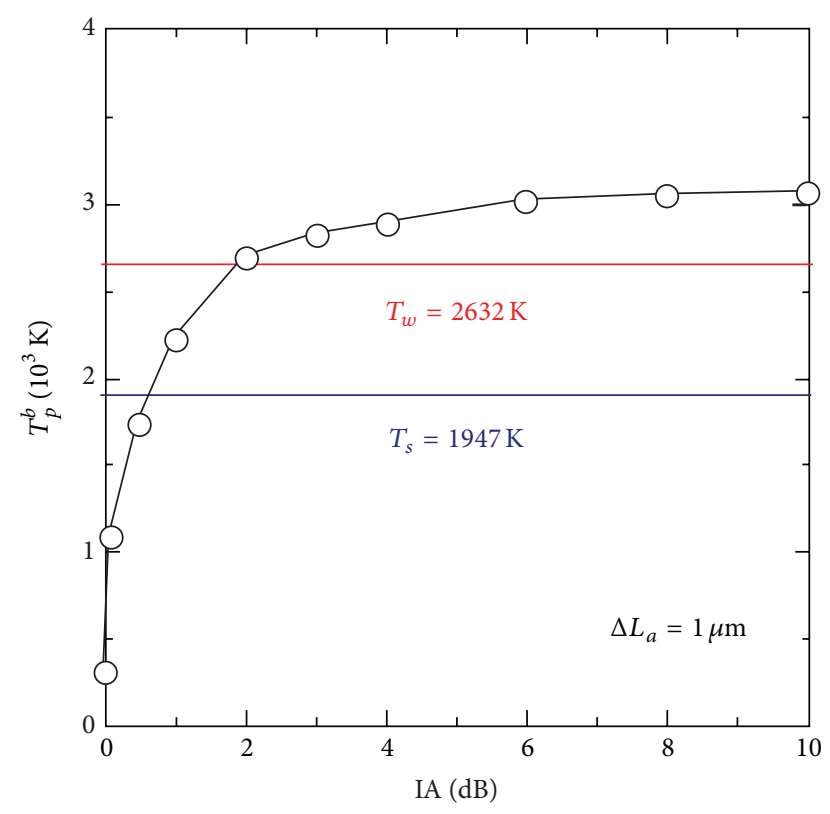

FIGURE 6: $T_{p}^{b}$ versus IA for spread carbon black layers when $P_{0}=1 \mathrm{~W}$ and $\lambda_{0}=1.48 \mu \mathrm{m}$.

a result, the quantity of heat required to raise the temperature from $T_{p}^{b}$ is canceled by the effective dissipation of the heat.

As shown in Figure 5, samples with IA $=6$ and $8 \mathrm{~dB}$ exhibit steep temperature gradients at the irradiation time of about $10 \mathrm{~ms}$. This behavior is considered to be related to the fiber fuse generation described below. In this case, the heat supplied from the heat source to the core layer is smaller than the heat required for fiber fuse initiation. As a result, the fiber fuse generation is hindered in these samples.

The relationship between $T_{p}^{b}$ and IA for the absorbent layer was examined. The result is shown in Figure 6.

The $T_{p}^{b}$ values for the absorbent layers with IA $\geq 3 \mathrm{~dB}$ are higher than $T_{w}$ for silica glass (see Figure 6). Therefore, it can be expected that the surfaces of the core layers will be damaged when IA $>3 \mathrm{~dB}$, as reported by Domingues et al. [24].

On the other hand, $T_{p}^{b}(2680 \mathrm{~K})$ in the case of IA $=2 \mathrm{~dB}$ is almost equal to $T_{w}(2632 \mathrm{~K})$. Thus, when IA $<2 \mathrm{~dB}$, it can be expected that the melting and flow of silica glass will not be observed in the core layers, which are adjacent to the absorbent layer.

Furthermore, $T_{p}^{b}(1780 \mathrm{~K})$ in the case of $\mathrm{IA}=0.5 \mathrm{~dB}$ is smaller than $T_{s}(1947 \mathrm{~K})$. From the viewpoint of reliability, IA $\leq 0.5 \mathrm{~dB}$ is desirable for maintaining the initial insertion loss of single-mode fiber-optic connectors.

\subsection{Fiber Fuse Generation Caused by Carbon-Black Adhesion.} The occurrence of a fiber fuse was reported by Domingues et al. [24]. Samples with IA $=4-8 \mathrm{~dB}$ exhibited the fiber fuse effect at $P_{0}=1.5 \mathrm{~W}$ when they were exposed to $\mathrm{CW}$ laser light with $\lambda_{0}=1.48 \mu \mathrm{m}$. The $T_{p}$ values around the absorbent layers with $\mathrm{IA}=4,8$, and $12 \mathrm{~dB}$ were calculated as a function of the irradiation time after the incidence of 1.2-2.6 W laser light $\left(\lambda_{0}=1.48 \mu \mathrm{m}\right)$. The calculated results are shown in Figure 7.

As shown in Figure $7, T_{p}$ values of $1.5 \times 10^{4} \mathrm{~K}$ or above occur $0.75-7.4 \mathrm{~ms}$ after laser light incidence. This rapid rise in the temperature initiates the fiber fuse phenomenon. The minimum initiation power $P_{\text {init }}$ at $\lambda_{0}=1.48 \mu \mathrm{m}$ required to generate a fiber fuse was estimated to be $2.25,1.62$, and $1.28 \mathrm{~W}$ when $\mathrm{IA}=4,8$, and $12 \mathrm{~dB}$, respectively. The minimum irradiation times $t_{\min }$ at $P_{0}=P_{\text {init }}$ were $7.4,4.3$, and $3.3 \mathrm{~ms}$ in the case of $\mathrm{IA}=4,8$, and $12 \mathrm{~dB}$, respectively.

The relationship between $P_{\text {init }}$ and IA was investigated. The calculated results are shown in Figure 8.

As shown in Figure 8, the estimated $P_{\text {init }}$ values of the samples with $\mathrm{IA}=4-8 \mathrm{~dB}$ are larger than $1.5 \mathrm{~W}$, and those with IA $\geq 10 \mathrm{~dB}$ exhibit $P_{\text {init }}$ values of less than $1.5 \mathrm{~W}$. On the other hand, Domingues et al. reported that samples with IA $=4-$ $8 \mathrm{~dB}$ exhibited the fiber fuse effect with the passage of time at $P_{0}=1.5 \mathrm{~W}$ [24]. These experimental results are different from the calculated results shown in Figure 8.

This discrepancy may be caused by the difference in the $\Delta L_{a}$ values of the absorbent layers. As shown by (5), $\alpha_{a}$ for the absorbent layer increases with decreasing $\Delta L_{a}$. In the calculation, the author assumed $\Delta L_{a}=1 \mu \mathrm{m}$. If $\Delta L_{a}$ is assumed to be $0.4 \mu \mathrm{m}$ in the fiber fuse generation experiments conducted by Domingues et al., the $\alpha_{a}$ values at IA $=4-8 \mathrm{~dB}$ in their experiments correspond to those at IA $=10-20 \mathrm{~dB}$ in this calculation. Furthermore, the fiber fuse occurs on the boundary between the core and the absorbent layer and is unrelated to the thickness of the absorbent layer. As a result, the samples with $\mathrm{IA}=4-8 \mathrm{~dB}$ investigated by Domingues et al. will exhibit the fiber fuse phenomenon at $P_{0}=1.5 \mathrm{~W}$ because the $P_{\text {init }}$ values of the samples with $\mathrm{IA}=10-20 \mathrm{~dB}$ shown in Figure 8 are less than $1.5 \mathrm{~W}$.

Next, the temperature field $T(r, z)$ was calculated at $t=$ $2.0,2.2$, and $2.4 \mathrm{~ms}$ after the incidence of the $1.8 \mathrm{~W}$ laser light for $\mathrm{IA}=8 \mathrm{~dB}$. The calculated results are shown in Figures 9-11, respectively.

As shown in Figure 9, the core center temperature near the end of the absorbent layer $(L \sim-15 \mu \mathrm{m})$ changes abruptly to a large value of about $2 \times 10^{4} \mathrm{~K}$ after $2 \mathrm{~ms}$. This rapid rise in the temperature initiates the fiber fuse phenomenon as shown in Figures 10 and 11. After 2.2 and $2.4 \mathrm{~ms}$, the high temperature front in the core layer reached $L$ values of -98 and $-181 \mu \mathrm{m}$, respectively. The average propagation velocity $v_{f}$ was estimated to be about $0.41 \mathrm{~m} / \mathrm{s}$ using these data. This value is close to the experimentally determined $v_{f}$ value of $0.38 \mathrm{~m} / \mathrm{s}[11,45]$.

4.3. Formation Process of Fiber Fuse around Absorbent Layer. A sudden temperature increase in an extremely short time was observed when a fiber fuse occurred as shown in Figure 7. To investigate the formation process of the fiber fuse, the author calculated the temperature field $T(r, z)$ at $t=0.5,1.4$, 1.5 , and $1.6 \mathrm{~ms}$ after the incidence of $1.8 \mathrm{~W}$ laser light for $\mathrm{IA}=8 \mathrm{~dB}$. The calculated results are shown in Figures 12-15, respectively.

As shown in Figures 12 and 13, the temperature rise between 0.5 and $1.4 \mathrm{~ms}$ was relatively slow. As the $T_{p}$ values 

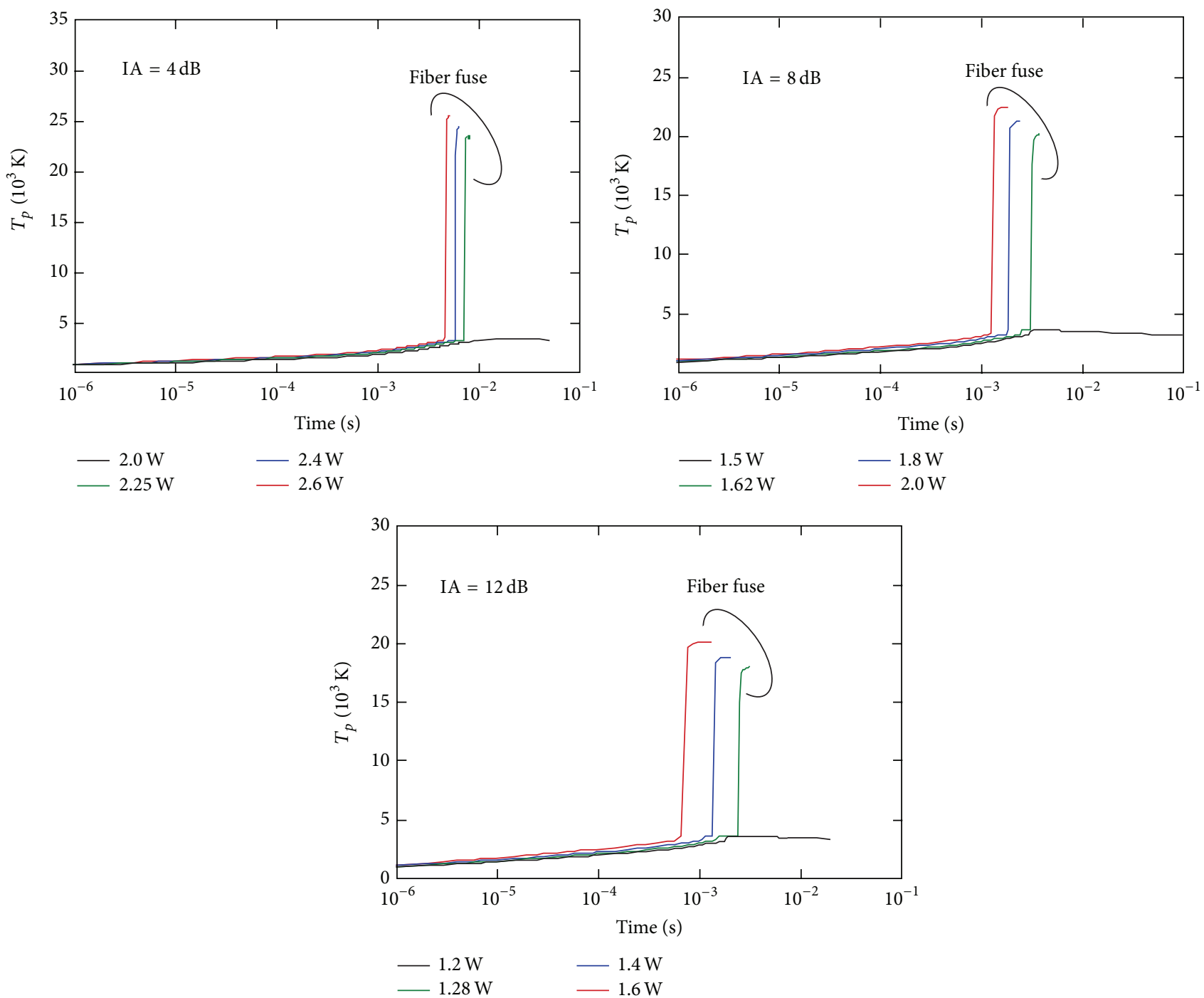

FIGURE 7: $T_{p}$ values around absorbent layers with $\mathrm{IA}=4,8$, and $12 \mathrm{~dB}(\Delta L=1 \mu \mathrm{m})$ versus irradiation time when $P_{0}=1.2-2.6 \mathrm{~W}$.

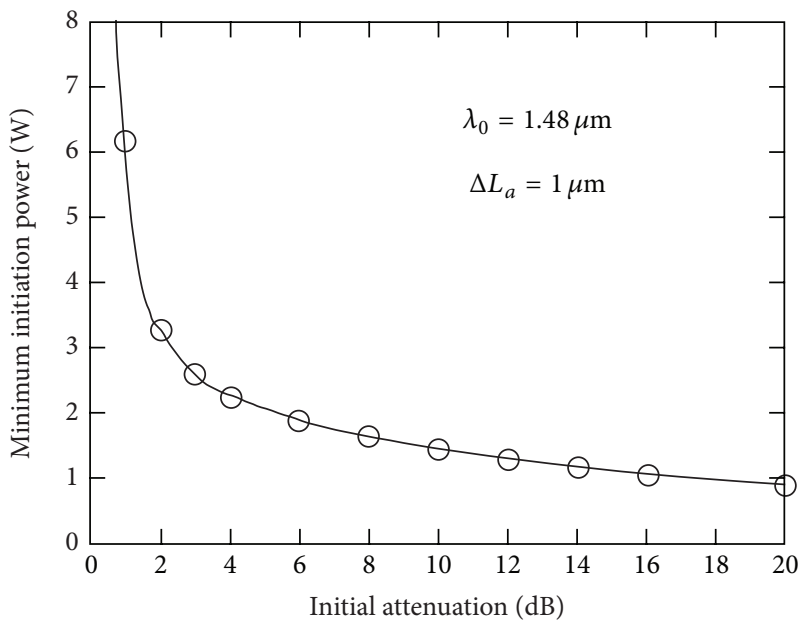

FIgURE 8: Minimum initiation power at $\lambda_{0}=1.48 \mu \mathrm{m}$ required to generate fiber fuse versus IA for absorbent layer $\left(\Delta L_{a}=1 \mu \mathrm{m}\right)$ between optical fibers.

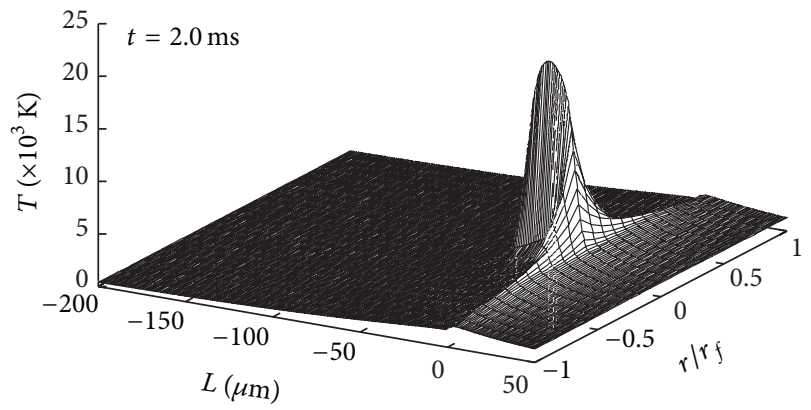

FIGURE 9: Temperature field around absorbent layer with $\mathrm{IA}=8 \mathrm{~dB}$ after $2 \mathrm{~ms}$ when $P_{0}=1.8 \mathrm{~W}$ and $\lambda_{0}=1.48 \mu \mathrm{m}$.

of 0.5 and $1.4 \mathrm{~ms}$ were 2520 and $3290 \mathrm{~K}$, respectively, $T_{p}$ increased by only $770 \mathrm{~K}$ in $0.9 \mathrm{~ms}$.

In contrast, $T_{p}$ reached $5340 \mathrm{~K}$ after $1.5 \mathrm{~ms}$ and exceeded $2.0 \times 10^{4} \mathrm{~K}$ after $1.6 \mathrm{~ms}$ (see Figures 14 and 15). This rapid 


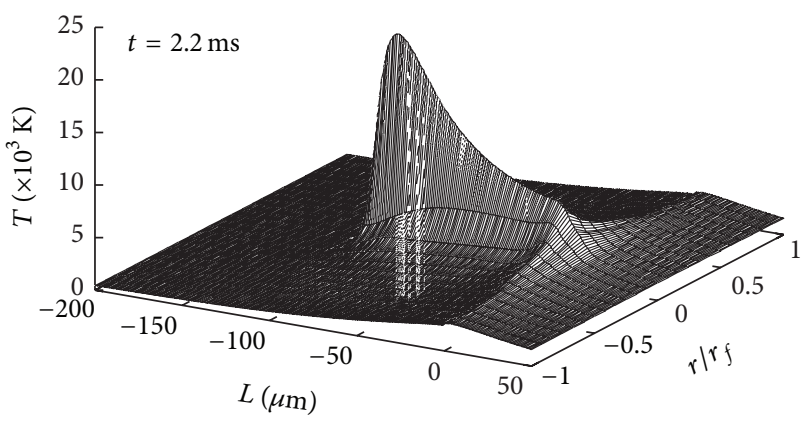

FIGURE 10: Temperature field around absorbent layer with $\mathrm{IA}=8 \mathrm{~dB}$ after $2.2 \mathrm{~ms}$ when $P_{0}=1.8 \mathrm{~W}$ and $\lambda_{0}=1.48 \mu \mathrm{m}$.

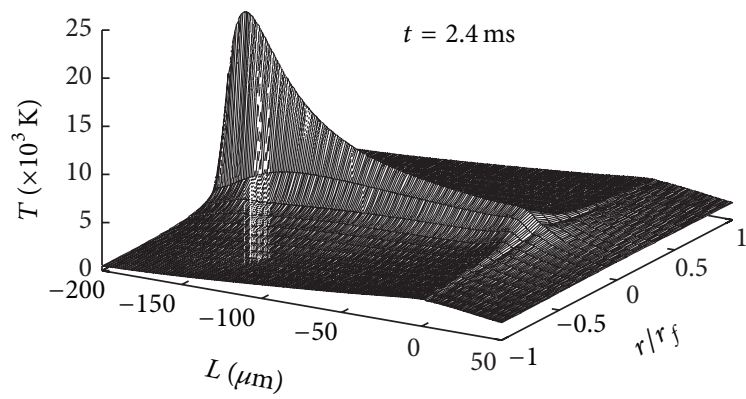

FIGURE 11: Temperature field around absorbent layer with IA $=8 \mathrm{~dB}$ after $2.4 \mathrm{~ms}$ when $P_{0}=1.8 \mathrm{~W}$ and $\lambda_{0}=1.48 \mu \mathrm{m}$.

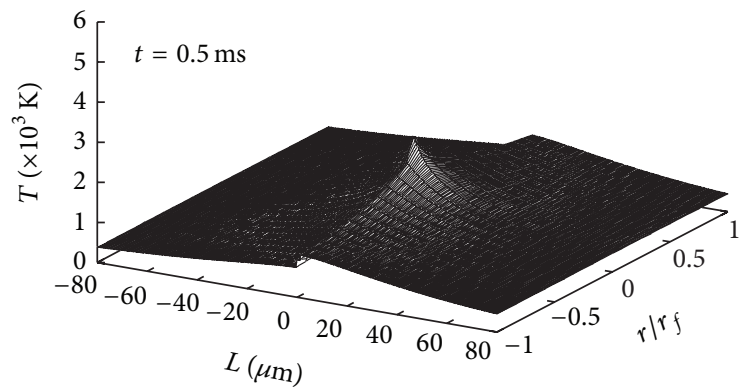

FIGURE 12: Temperature field around absorbent layer with IA $=8 \mathrm{~dB}$ after $0.5 \mathrm{~ms}$ when $P_{0}=1.8 \mathrm{~W}$ and $\lambda_{0}=1.48 \mu \mathrm{m}$.

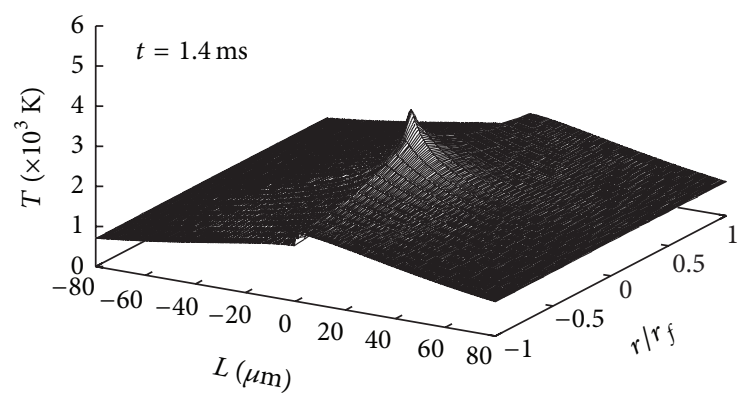

FIGURE 13: Temperature field around absorbent layer with $\mathrm{IA}=8 \mathrm{~dB}$ after $1.4 \mathrm{~ms}$ when $P_{0}=1.8 \mathrm{~W}$ and $\lambda_{0}=1.48 \mu \mathrm{m}$.

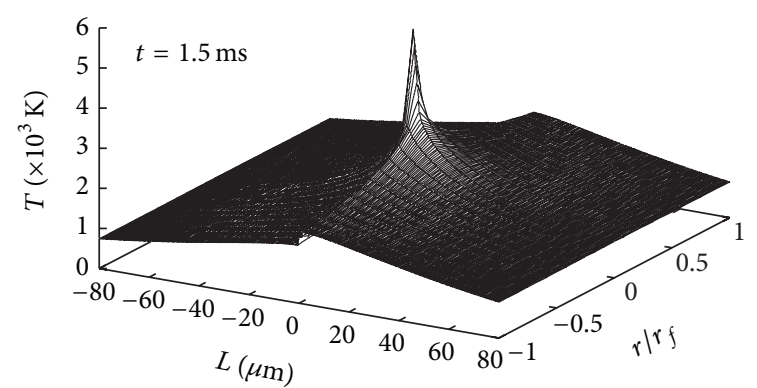

FIGURE 14: Temperature field around absorbent layer with IA $=8 \mathrm{~dB}$ after $1.5 \mathrm{~ms}$ when $P_{0}=1.8 \mathrm{~W}$ and $\lambda_{0}=1.48 \mu \mathrm{m}$.

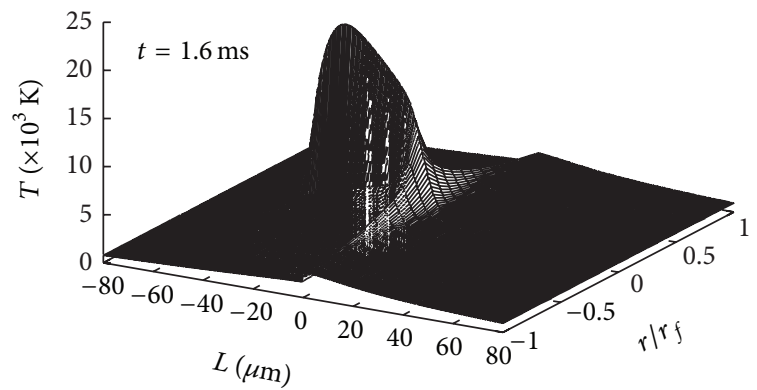

FIGURE 15: Temperature field around absorbent layer with IA $=8 \mathrm{~dB}$ after $1.6 \mathrm{~ms}$ when $P_{0}=1.8 \mathrm{~W}$ and $\lambda_{0}=1.48 \mu \mathrm{m}$.

rise in the temperature initiates the fiber fuse phenomenon as shown in Figures 9-11.

A sudden temperature change was not seen even after $100 \mathrm{~ms}$ when $P_{0}$ was $1 \mathrm{~W}$ (see Figure 5). In this case, $T_{p}$ tended to rise at about $10 \mathrm{~ms}$ and then decreased. This means that $P_{0}$ of $1 \mathrm{~W}$ is insufficient for $T_{p}$ to increase from $3000 \mathrm{~K}$ to over $5000 \mathrm{~K}$

Why did a fiber fuse occur above $5000 \mathrm{~K}$ ? One reason is the light absorption behavior of the optical fiber at high temperatures. The author calculated the temperature dependence of the absorption coefficient $(\alpha)$ at $1.48 \mu \mathrm{m}$ when heating an SMF-28 optical fiber, using the procedure described in [12, 26]. The result is shown in Figure 16. As shown in Figure 16, the $\alpha$ value $\left(11.3 \times 10^{4} \mathrm{~m}^{-1}\right)$ at $5000 \mathrm{~K}$ is larger than that $\left(6.5 \times 10^{4} \mathrm{~m}^{-1}\right)$ at $3000 \mathrm{~K}$. A rapid change in $\alpha$ occurs when the temperature changes from $2000 \mathrm{~K}$ to $3000 \mathrm{~K}$. In contrast, there is little change in $\alpha$ when the temperature changes from $4000 \mathrm{~K}$ to $7000 \mathrm{~K}$ (see Figure 16).

The radiating part of a fiber fuse consists of low-density ionized gas plasma, whose temperature exceeds $4000 \mathrm{~K}$ [46]. To maintain the ionized gas plasma state in the fiber fuse, heat must be supplied constantly even if the temperature changes. To this end, it is necessary for $\alpha$ to take roughly the same value when the temperature changes while remaining above $4000 \mathrm{~K}$. The temperature dependence of $\alpha$ for the SMF-28 fiber satisfies this requirement (see Figure 16). This indicates that a core temperature of more than $4000 \mathrm{~K}$ is necessary to generate and maintain a fiber fuse. The temperatures of the fiber fuse estimated and/or measured experimentally were $5400 \mathrm{~K}$ [6] and $5800-6500 \mathrm{~K}$ [47]. The theoretically 


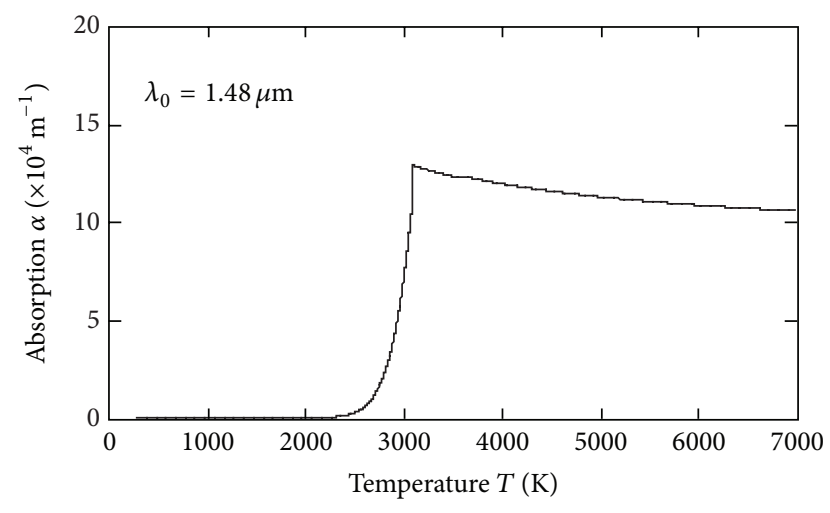

FIgURE 16: Absorption coefficient of SMF-28 at $1.48 \mu \mathrm{m}$ versus temperature.

estimated temperature of $>4000 \mathrm{~K}$ for fiber fuse generation and maintenance does not contradict these experimental results.

Next the author investigated the stability of low-density ionized gas plasma in the fiber-optic connector, where the absorbent (carbon black) enters the gap between the end faces of SMF-28 optical fibers. The gas plasma exhibits high temperature and high pressure [48] because it is confined in a small space of about $20 \mu \mathrm{m}$ in width [49] around the core layer. When temperature of the gas plasma reaches $5000 \mathrm{~K}$, its pressure becomes about $5000 \mathrm{~atm}$. This high pressure of the plasma is maintained in the optical fiber because the leak of the plasma is obstructed by neighboring rigid silica glass.

On the other hand, in the fiber-optic connector, the end face of the fiber is constantly compressed with high pressure of about $5000 \mathrm{~atm}$, which is caused by the compressive force in the connector. Silica glass at the end face is melted and changes to densely packed $\mathrm{SiO}_{x}(x<2)$ [26] with increasing temperature. And gaseous $\mathrm{SiO}_{x}$ molecules decompose and become ionized gas plasma at high temperatures of about $5000 \mathrm{~K}$ [46]. Therefore, high pressure $(<5000 \mathrm{~atm})$ of the plasma at temperature of $<5000 \mathrm{~K}$ can be kept by the help of the compressive force in the connector.

However, with increasing temperature, pressure of the plasma exceeds the acceptable pressure (about $5000 \mathrm{~atm}$ ) for maintaining the primary (equilibrium) conditions of the plasma at the end face.

The temperatures of the core center at the end face ( $L=$ $-0.5 \mu \mathrm{m}$ ) abutting the absorbent (carbon black) layer with $\mathrm{IA}=8 \mathrm{~dB}(\Delta L=1 \mu \mathrm{m})$ were calculated as a function of the irradiation time after the incidence of the $1.62,2$, and $3 \mathrm{~W}$ laser light. The calculated result is shown in Figure 17. In the temporal axis of this figure, the time of $0.1 \mathrm{~ms}$ is the start time for sudden temperature rise. As shown in Figure 17, during short time (about $0.5 \mathrm{~ms}$ ), temperature at the end face exceeds $5000 \mathrm{~K}$ after a temperature rise began.

Next the temperature fields at the end face $(L=-0.5 \mu \mathrm{m})$ along the $r$ direction were calculated about three $P_{0}$ conditions shown in Figure 17 at a time of $0.1 \mathrm{~ms}$ after the temperature rise start. The calculated result is shown in Figure 18. As shown in Figure 18, the temperatures at the outer

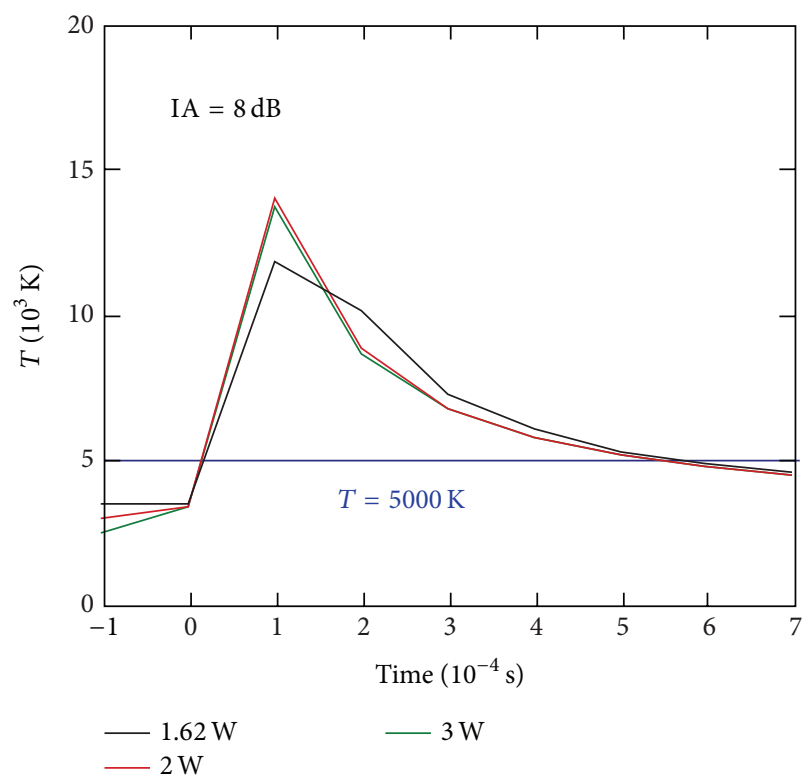

FIGURE 17: Temperature of the core center at the end face abutting the carbon black layer with $\mathrm{IA}=8 \mathrm{~dB}(\Delta L=1 \mu \mathrm{m})$ versus irradiation time when $P_{0}=1.62,2$, and $3 \mathrm{~W}$ and $\lambda_{0}=1.48 \mu \mathrm{m}$.

cladding surfaces $\left(r / r_{f}= \pm 1\right)$ of three samples are lower than the softening point $\left(T_{s}=1947 \mathrm{~K}\right)$ of the silica glass when $t=$ $0.1 \mathrm{~ms}$ after the temperature rise start. This means that high pressure of the plasma in the optical fiber is kept in the radial direction because the leak of the plasma through the cladding layer is obstructed by neighboring rigid silica glass.

As a result, leakage of the gas plasma into neighboring liquid carbon layer is generated during the short time (about $0.5 \mathrm{~ms}$ ) after the temperature rise start, and the plasma is expanded. This results in a reduction of the pressure of the plasma, and its pressure falls to $5000 \mathrm{~atm}$ at this place. Simultaneously, the temperature of the gas plasma decreases, and it falls to $5000 \mathrm{~K}$. This pressure and temperature drop disturbs equilibrium of the plasma at the end face. The plasma is going to become uniform, and the instability of the plasma will be caused around this place.

If the plasma is small in size and located close to the end face, the instability of the plasma may lead to the termination of a fiber fuse.

The temperature fields of the core center along the $z$ direction were calculated about three $P_{0}$ conditions shown in Figure 17 at a time of $0.1 \mathrm{~ms}$ after the temperature rise start. The calculated result is shown in Figure 19. In this figure, blue triangles indicate the places of the highest temperature.

As shown in Figure 19, the gas plasma in the sample with $P_{0}=1.62 \mathrm{~W}$, which is $P_{\text {init }}$ when IA $=8 \mathrm{~dB}$, exhibits its thermal peak at $L=-2.5 \mu \mathrm{m}$. This place is very near the fiber end face $(L=-0.5 \mu \mathrm{m})$. Therefore, if a fiber fuse occurs and the fiber fuse propagation begins in this sample, the fuse may be terminated due to the instability of the gas plasma. Similar phenomena of fiber fuse termination were reported by Kurokawa et al. [50, 51] in some studies about hole-assisted fiber (HAF). 


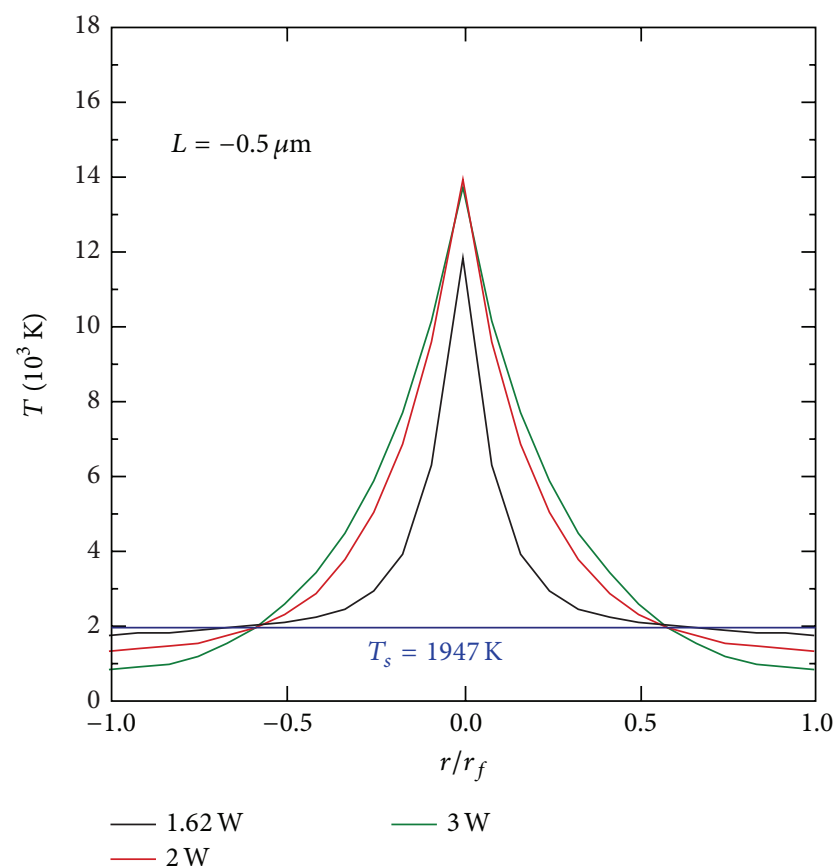

FIGURE 18: Temperature fields at the end face abutting the carbon black layer with $\mathrm{IA}=8 \mathrm{~dB}(\Delta L=1 \mu \mathrm{m})$ at $0.1 \mathrm{~ms}$ after the temperature rise start when $P_{0}=1.62,2$, and $3 \mathrm{~W}$ and $\lambda_{0}=1.48 \mu \mathrm{m}$.

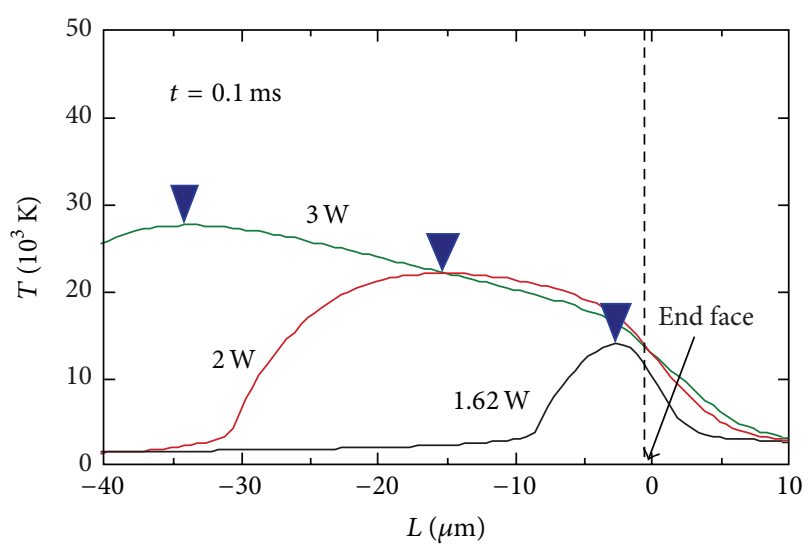

FIGURE 19: Temperature fields around the end face abutting the carbon black layer with $\mathrm{IA}=8 \mathrm{~dB}(\Delta L=1 \mu \mathrm{m})$ at $0.1 \mathrm{~ms}$ after the temperature rise start when $P_{0}=1.62,2$, and $3 \mathrm{~W}$ and $\lambda_{0}=1.48 \mu \mathrm{m}$. Blue triangles indicate the places of the highest temperature.

The relationship between the fiber fuse termination phenomenon and instability of the plasma has yet to be sufficiently clarified. It largely depends upon future multilateral studies.

\section{Conclusions}

The evolution of both the core melting and fiber fuse phenomena in a single-mode fiber-optic connector was studied theoretically. Carbon black was chosen as a light-absorbent material. A thin absorbent layer with thickness of $1 \mu \mathrm{m}$ order was assumed to be formed between the fiber end faces in the connector. The heat flow process of the core, which caused the core to melt or the fiber fuse phenomenon, was theoretically calculated with the explicit finite-difference method. The calculated results were compared with experimental results. From the viewpoint of reliability, it was found that initial attenuation of less than $0.5 \mathrm{~dB}$ is desirable to prevent the core from melting in the single-mode fiber-optic connectors when the input laser power is $1 \mathrm{~W}$ at a wavelength of $1.48 \mu \mathrm{m}$. Furthermore, a core temperature of more than $4000 \mathrm{~K}$ is necessary to generate and maintain a fiber fuse.

\section{Competing Interests}

The author declares no competing interests.

\section{References}

[1] A. Sano, T. Kobayashi, E. Yoshida, and Y. Miyamoto, "Ultra-high capacity optical transmission technologies for $100 \mathrm{Tbit} / \mathrm{s}$ optical transport networks," IEICE Transactions on Communications, vol. 94, no. 2, pp. 400-408, 2011.

[2] M. Nakazawa, "Evolution of EDFA from single-core to multicore and related recent progress in optical communication," Optical Review, vol. 21, no. 6, pp. 862-874, 2014.

[3] T. Morioka, "New generation optical infrastructure technologies: 'EXAT initiative' towards 2020 and beyond," in Proceedings of the 14th OptoElectronics and Communications Conference (OECC '09), pp. 1-2, IEEE, Hong Kong, July 2009.

[4] R. Kashyap and K. J. Blow, "Observation of catastrophic selfpropelled self-focusing in optical fibres," Electronics Letters, vol. 24, no. 1, pp. 47-49, 1988.

[5] R. Kashyap, "Self-propelled self-focusing damage in optical fibres," in Proceedings of the 10th International Conference on Lasers and Applications, pp. 859-866, 1988.

[6] D. P. Hand and P. S. Russell, "Solitary thermal shock waves and optical damage in optical fibers: the fiber fuse," Optics Letters, vol. 13, no. 9, pp. 767-769, 1988.

[7] D. P. Hand and P. St. J. Russell, "Soliton-like thermal shockwaves in optical fibres: origin of periodic damage tracks," in Proceedings of the 14th European Conference on Optical Communication (ECOC '88), Conference Publication no. 292, pp. 111-114, Brighton, UK, September 1988.

[8] P. André, A. Rocha, F. Domingues, and M. Facão, "Thermal effects in optical fibres," in Developments in Heat Transfer, M. A. dos Santos Bernardes, Ed., chapter 1, pp. 1-20, InTech, Rijeka, Croatia, 2011.

[9] S. Todoroki, "Fiber fuse propagation behavior," in Selected Topics on Optical Fiber Technology, M. Yasin, S. W. Harun, and H. Arof, Eds., vol. 20, chapter 20, pp. 551-570, InTech, Rijeka, Croatia, 2012.

[10] R. Kashyap, "The fiber fuse-from a curious effect to a critical issue: a 25th year retrospective," Optics Express, vol. 21, no. 5, pp. 6422-6441, 2013.

[11] S. Todoroki, Fiber Fuse, NIMS Monographs, Springer, Tokyo, Japan, 2014.

[12] Y. Shuto, "Simulation of fiber fuse phenomenon in single-mode optical fibers," in Advances in Optical Fiber Technology, M. Yasin, H. Arof, and S. W. Harun, Eds., chapter 5, pp. 159-197, InTech, Rijeka, Croatia, 2014. 
[13] D. D. Davis Jr., S. C. Mettler, and D. J. DiGiovanni, "Experimental data on the fiber fuse," in 27th Annual Boulder Damage Symposium: Laser-Induced Damage in Optical Materials, vol. 2714 of Proceedings of SPIE, pp. 202-210, October 1995.

[14] D. D. Davis, S. C. Mettler, and D. J. DiGiovanni, "A comparative evaluation of fiber fuse models," in Laser-Induced Damage in Optical Materials, H. E. Bennett, A. H. Guenther, M. R. Kozlowski, B. E. Newnam, and M. J. Soileau, Eds., vol. 2966 of SPIE Proceedings, pp. 592-606, SPIE, Bellingham, Wash, USA, 1996.

[15] S.-I. Todoroki, "Origin of periodic void formation during fiber fuse," Optics Express, vol. 13, no. 17, pp. 6381-6389, 2005.

[16] S.-I. Todoroki, "In situ observation of modulated light emission of fiber fuse synchronized with void train over hetero-core splice point," PLoS ONE, vol. 3, no. 9, Article ID e3276, 2008.

[17] F. Domingues, A. R. Frias, P. Antunes, A. O. P. Sousa, R. A. S. Ferreira, and P. S. André, "Observation of fuse effect discharge zone nonlinear velocity regime in erbium-doped fibres," Electronics Letters, vol. 48, no. 20, pp. 1295-1296, 2012.

[18] S.-I. Todoroki, "Fiber fuse propagation modes in typical singlemode fibers," in Proceedings of the Optical Fiber Communication Conference and Exposition and the National Fiber Optic Engineers Conference (OFC/NFOEC '13), OSA Technical Digest, paper JW2A.11, pp. 1-3, Optical Society of America, Anaheim, Calif, USA, March 2013.

[19] P. F. C. Antunes, M. F. F. Domingues, N. J. Alberto, and P. S. André, "Optical fiber microcavity strain sensors produced by the catastrophic fuse effect," IEEE Photonics Technology Letters, vol. 26, no. 1, pp. 78-81, 2014.

[20] G.-R. Lin, M. D. Baiad, M. Gagne, W.-F. Liu, and R. Kashyap, "Harnessing the fiber fuse for sensing applications," Optics Express, vol. 22, no. 8, pp. 8962-8969, 2014.

[21] M. F. F. Domingues, T. B. Paixão, E. F. T. Mesquita et al., "Liquid hydrostatic pressure optical sensor based on microcavity produced by the catastrophic fuse effect," IEEE Sensors Journal, vol. 15, no. 10, pp. 5654-5658, 2015.

[22] M. De Rosa, J. Carberry, V. Bhagavatula, K. Wagner, and C. Saravanos, "High-power performance of single-mode fiberoptic connectors," Journal of Lightwave Technology, vol. 20, no. 5, pp. 879-885, 2002.

[23] S. Yanagi, S. Asakawa, and R. Nagase, "Characteristics of fibreoptic connector at high-power optical incidence," Electronics Letters, vol. 38, no. 17, pp. 977-978, 2002.

[24] F. Domingues, A. M. Rocha, and P. S. André, "High-power effects in damaged and contaminated optical fiber connectors," Microwave and Optical Technology Letters, vol. 53, no. 11, pp. 2485-2488, 2011.

[25] K. Seo, N. Nishimura, M. Shiino, R. Yuguchi, and H. Sasaki, "Evaluation of high-power endurance in optical fiber links," Furukawa Review, no. 24, pp. 17-22, 2003.

[26] Y. Shuto, "Heat conduction modeling of fiber fuse in singlemode optical fibers," Journal of Photonics, vol. 2014, Article ID 645207, 11 pages, 2014.

[27] B. Jensen, "The quantum extension of the Drude-Zener theory in polar semiconductors," in The quantum extension of the Drude-Zener theory in polar semiconductors, E. D. Palik, Ed., chapter 9, Academic Press, New York, NY, USA, 1985.

[28] P. R. Wallace, "The band theory of graphite," Physical Review, vol. 71, no. 9, pp. 622-634, 1947.

[29] E. A. Taft and H. R. Philipp, "Optical properties of graphite," Physical Review, vol. 138, no. 1A, pp. A197-A202, 1965.
[30] D. L. Greenaway, G. Harbeke, F. Bassani, and E. Tosatti, "Anisotropy of the optical constants and the band structure of graphite," Physical Review, vol. 178, no. 3, pp. 1340-1348, 1969.

[31] R. Kashyap, A. Sayles, and G. F. Cornwell, "Heat flow modeling and visualization of catastrophic self-propagating damage in single-mode optical fibres at low powers," Proceedings of the Society of Photo-Optical Instrumentation Engineers, vol. 2966, pp. 586-591, 1996.

[32] A. I. Savvatimskiy, "Measurements of the melting point of graphite and the properties of liquid carbon (a review for 19632003)," Carbon, vol. 43, no. 6, pp. 1115-1142, 2005.

[33] F. P. Bundy, "Pressure-temperature phase diagram of elemental carbon," Physica A: Statistical Mechanics and Its Applications, vol. 156, no. 1, pp. 169-178, 1989.

[34] M. Joseph, N. Sivakumar, and P. Manoravi, "High temperature vapour pressure studies on graphite using laser pulse heating," Carbon, vol. 40, no. 11, pp. 2031-2034, 2002.

[35] N. P. Bansal and R. H. Doremus, Handbook of Glass Properties, Academic Press, New York, NY, USA, 1986.

[36] R. Brückner, "Properties and structure of vitreous silica. II," Journal of Non-Crystalline Solids, vol. 5, no. 3, pp. 177-216, 1971.

[37] G. Hofmaier and G. Urbain, "The viscosity of pure silica," in Science of Ceramics, G. H. Stewart, Ed., vol. 4, chapter 1, pp. 2532, The British Ceramic Society, Manchester, UK, 1968.

[38] IEC 61754-4:2013, Fibre optic interconnecting devices and passive components-Fibre optic connector interfaces-Part 4: Type SC connector family.

[39] N. Suzuki, Y. Iwahara, M. Saruwatari, and K. Nawata, "Ceramic capillary connector for $1.3 \mu \mathrm{m}$ single-mode fibres," Electronics Letters, vol. 15, no. 25, pp. 809-810, 1979.

[40] R. Nagase, T. Shintaku, and E. Sugita, "Effect of axial compressive force for connection stability in PC optical fibre connectors," Electronics Letters, vol. 23, no. 3, pp. 103-105, 1987.

[41] A. Sharma, D. Agarwal, and J. Singh, "Study of curing kinetics and thermal degradation of UV curable epoxy acrylate resin," E-Journal of Chemistry, vol. 5, no. 4, pp. 904-913, 2008.

[42] M. Shoji, Heat Transfer Textbook, Appendix F, University of Tokyo Press, Tokyo, Japan, 1995.

[43] Chemical Data Book, chapter 9, Chemical Society of Japan, Tokyo, Japan, 3rd edition, 1984.

[44] H. S. Carslaw and J. C. Jaeger, Conduction of Heat in Solids, chapter 13, Oxford University Press, Oxford, UK, 2nd edition, 1959.

[45] K. S. Abedin and M. Nakazawa, "Real time monitoring of a fiber fuse using an optical time-domain reflectometer," Optics Express, vol. 18, no. 20, pp. 21315-21321, 2010.

[46] Y. Shuto, "Evaluation of high-temperature absorption coefficients of ionized gas plasmas in optical fibers," IEEE Photonics Technology Letters, vol. 22, no. 3, pp. 134-136, 2010.

[47] E. M. Dianov, V. E. Fortov, I. A. Bufetov et al., "High-speed photography, spectra, and temperature of optical discharge in silica-based fiberss," IEEE Photonics Technology Letters, vol. 18, no. 6, pp. 752-754, 2006.

[48] E. M. Dianov, I. A. Bufetov, and A. A. Frolov, "Destruction of silica fiber cladding by the fuse effect," Optics Letters, vol. 29, no. 16, pp. 1852-1854, 2004.

[49] K. Kurokawa and N. Hanzawa, "Fiber fuse propagation and its suppression in hole-assisted fibers," IEICE Transactions on Communications, vol. 94, no. 2, pp. 384-391, 2011. 
[50] K. Kurokawa, N. Hanzawa, K. Tsujikawa, and S. Tomita, "Holesize dependence of fiber fuse propagation in hole-assisted fiber (HAF)," in Proceedings of the 17th Microopics Conference (MOC '11), IEEE, Sendai, Japan, 2011.

[51] K. Kurokawa and N. Hanzawa, "Suppression of fiber fuse propagation and its break in compact fiber fuse terminator," in Proceedings of the 18th OptoElectronics and Communications Conference Held Jointly with International Conference on Photonics in Switching (OECC/PS '13), pp. WS4-WS5, July 2013. 

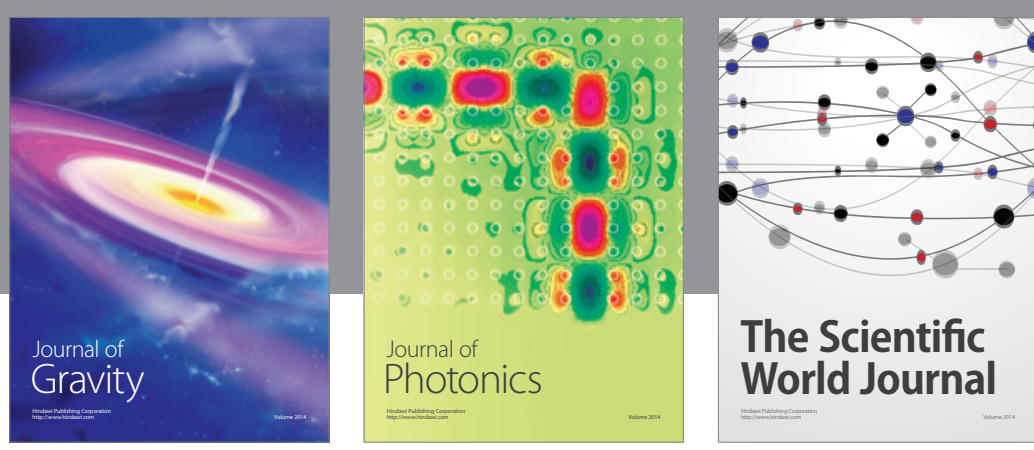

The Scientific World Journal
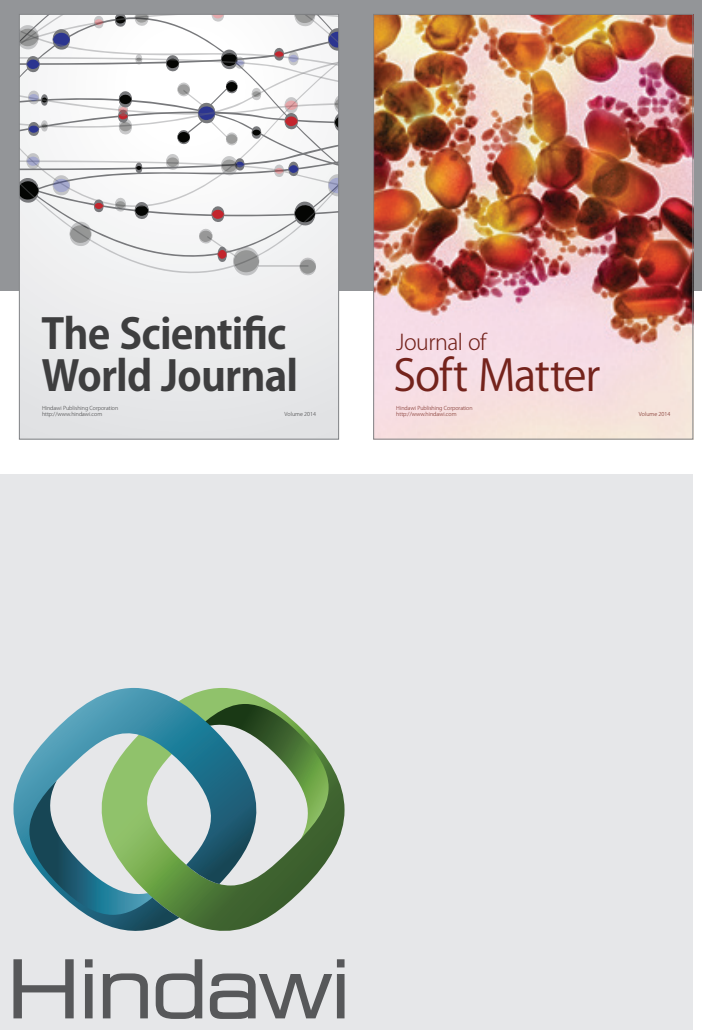

Submit your manuscripts at

http://www.hindawi.com

nternational Journal of

Statistical Mechanics
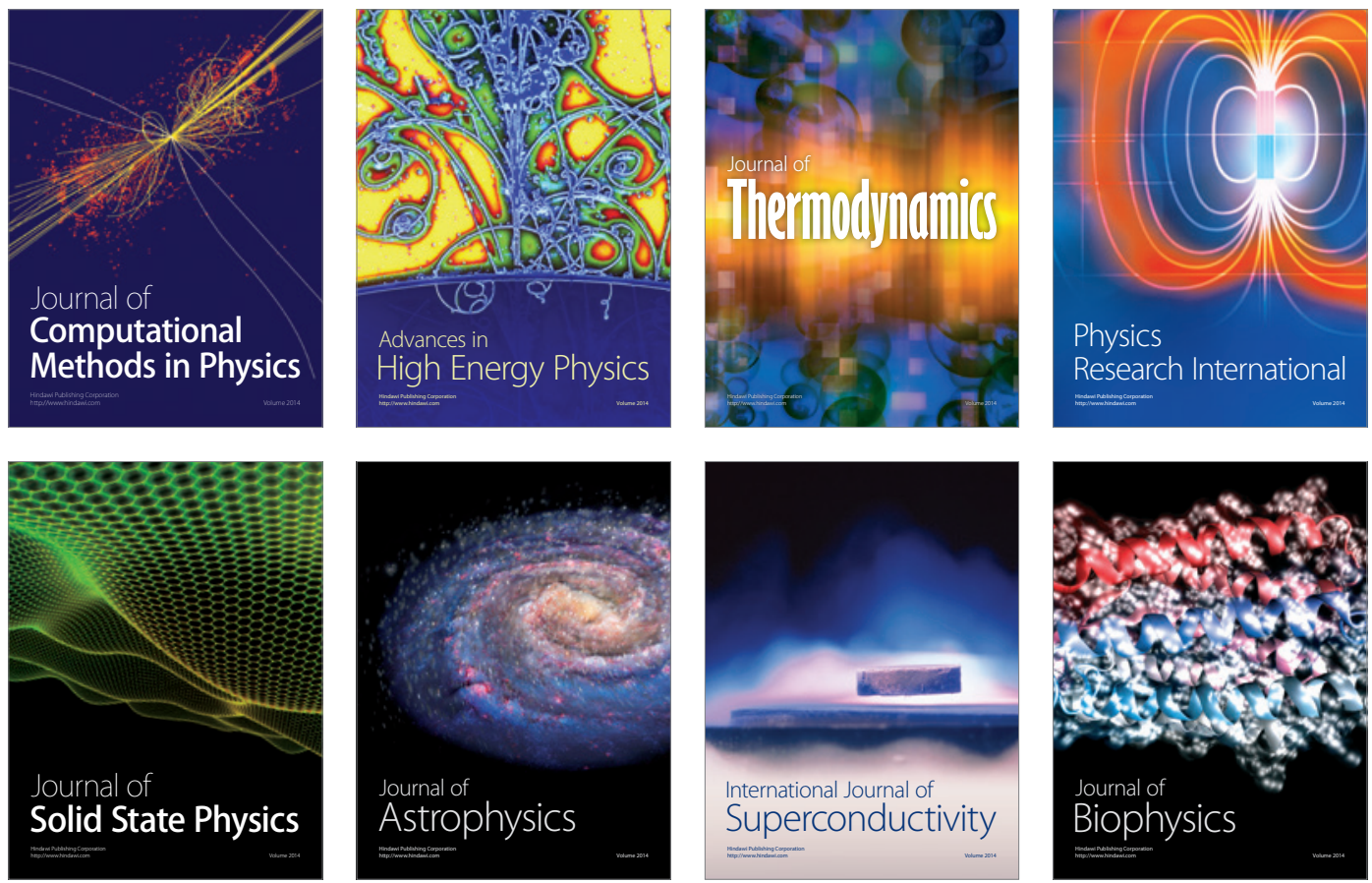
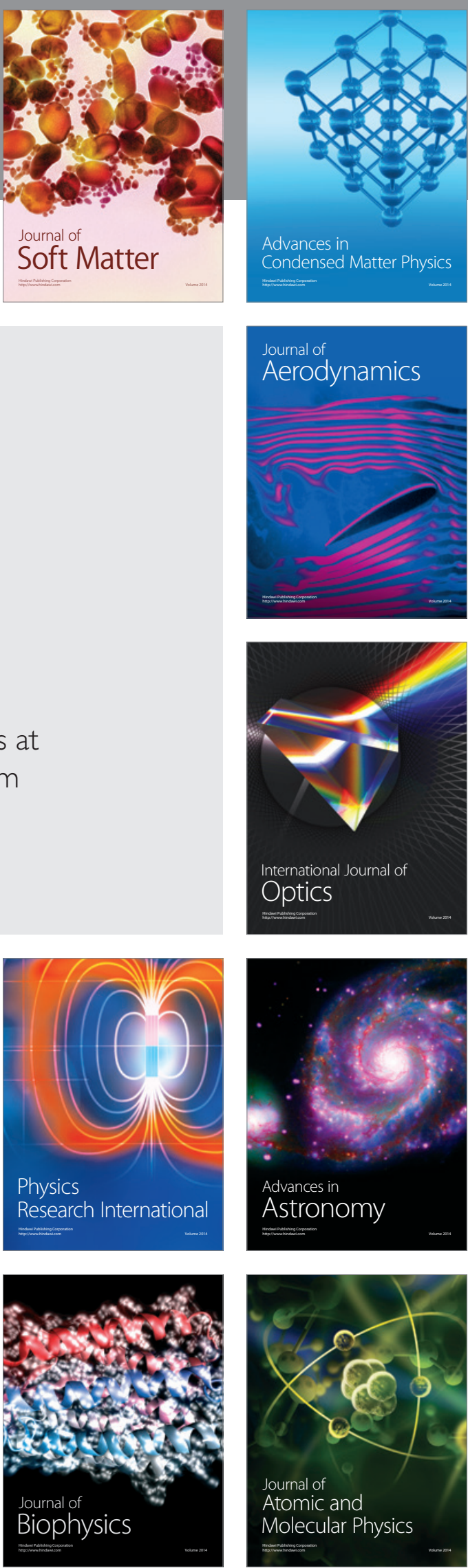